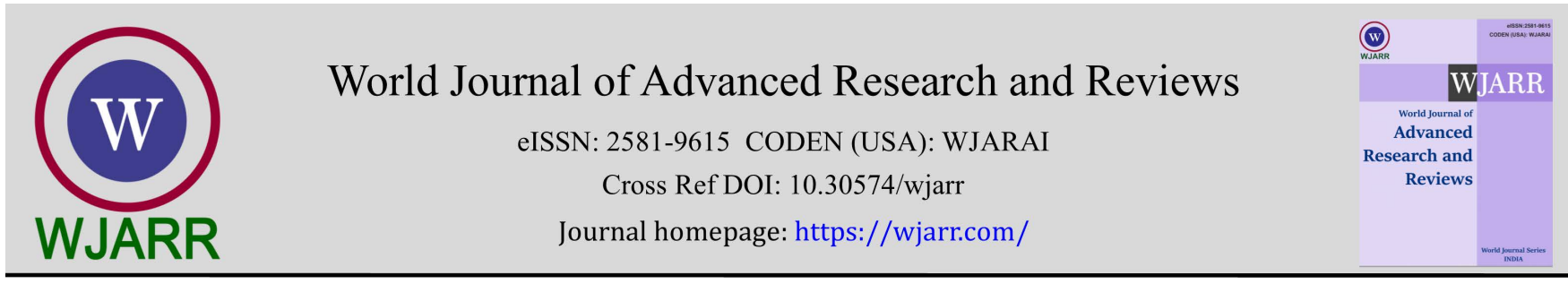

(RESEARCH ARTicle)

\title{
Mini scale production of Brazilian Cherry Fruits (Eugenia uniflora L.) for the first time in NSTU campus in Bangladesh \& the determination of antioxidant activity of different solvent extracts of ripe and non-ripe Brazilian Cherry Fruits
}

\author{
Subodh Kumar Sarkar ${ }^{1,}{ }^{*}$, Tatsuro Miyaji ${ }^{2}$ and Jin-ichi Sasaki ${ }^{3}$ \\ ${ }^{1}$ Department of Biochemistry and Molecular Biology, Noakhali Science and Technology University, Noakhali -3814, \\ Bangladesh. \\ 2 Department of Materials and Life Science, Faculty of Science and Technology, Shizuoka Institute of Science and \\ Technology, 2200-2 Toyosawa, Fukuroi, Shizuoka 437-8555, Japan. \\ ${ }^{3}$ Hirosaki University of Health Sciences, 66-1 Honcho, Hirosaki 036-8564, Japan.
}

World Journal of Advanced Research and Reviews, 2021, 10(03), 048-060

Publication history: Received on 24 April 2021; revised on 01 June 2021; accepted on 06 June 2021

Article DOI: https://doi.org/10.30574/wjarr.2021.10.3.0246

\begin{abstract}
The aim of this research is to cultivate Brazilian Cherry Fruits (Eugenia uniflora L.) Plants in NSTU (Noakhali Science and Technology University) Campus, Noakhali, Bangladesh for fruits production and to determine the qualitative antioxidant test, antioxidant activities and total phenolic content of different solvent extracts (Water, Methanol and Ethanol) of Ripe Brazilian Cherry Fruits in Red Color and compare those activities with non-ripe Brazilian Cherry fruits in Green color. The qualitative antioxidant test was determined by simple TLC method and antioxidant activity was determined by DPPH radical inhibition method while the total phenolic content was determined by Folin-Ciocalteu method. The result of the qualitative determination of Antioxidant test indicated that all extracts of Brazilian Cherry Fruits contain high antioxidant compounds. Among the analyzed fruits of all extracts, in both Ripe and Non-Ripe stage, the water extract of non-ripe Brazilian Cherry Fruits (BC-GC-W) showed the highest DPPH radical scavenging activity $(73.66 \%)$ and showed the lowest $\mathrm{IC}_{50}$ of DPPH scavenging activity $(1.01 \mu \mathrm{g} / \mathrm{ml})$ which may be due to the presence of high content of Vitamin C. Among all extracts of Ripe and non-ripe, the methanol extract of non-ripe Brazilian Cherry Fruits in Green Color (BC-GC-M) was found to be highest total phenolic content $111.52 \mathrm{mg}$ GAE/100g, and the ethanol extracts of Ripe Brazilian Cherry Fruits in Red Color (BC-RC-E) was found to be lowest total phenolic content, 106.004 mg GAE/100g. The overall results that were obtained in this study will be one of the important key strategies by adding this fruits in the diet chart to prevent and fight against infection recently caused by COVID-19 in worldwide and other infectious diseases by increasing our body immunity in the long term and this fruits also will be useful as a raw materials in the pharmaceutical and food industries to prepare drugs and food products.
\end{abstract}

Keywords: Brazilian Cherry Fruits; Antioxidants; DPPH; Phenolic, Free radicals; Gallic acid

\section{Introduction}

In our country, Bangladesh many varieties of fruits like mango, pineapple, lichi, guava, and jack fruit etc. are producing in a large scale and contributing in the poverty reduction and household food security of rural peoples. A sweet finest nutritionally rich foreign fruits, Brazilian Cherry (Eugenia uniflora L.) may also contribute in the poverty reduction and household food security as well as to improve the immunity to prevent different types of diseases. Eugenia uniflora L. is a tropical fruit bearing shrub or small tree in the Myrtaceae family. Common names include Surinam Cherry, Pitanga, Brazilian Cherry, Florida Cherry, Cayenne Cherry, Barbados cherry, French Cherry, Pitanga Cherry, and Red Brazil

\footnotetext{
* Corresponding author: Subodh Kumar Sarka e mail: sksarkar11bio@yahoo.com
}

Department of Biochemistry and Molecular Biology, Noakhali Science and Technology University, Noakhali -3814, Bangladesh. Copyright (c) 2021 Author(s) retain the copyright of this article. This article is published under the terms of the Creative Commons Attribution Liscense 4.0. 
cherry. Surinam Cherry was botanically described as a plant which grows in Pisa garden at Italy. It was believed to get introduced from Goa (India). The seeds were brought by the Portuguese voyagers to India from Brazil. It was naturalized in Argentina, Colombia and Venezuela. It is cultivated as an ornamental plant in Samoa, Hawaii, Ceylon and India. But it is occasionally grown in Southern China, Tropical Africa and Philippines. It is a widely found in South American countries, mainly in Brazil, Argentina, Uruguay and Paraguay [1]. Fruiting is generally profuse with hundreds or thousands of fruits per cycle and trees sometimes fruiting 2 to 3 times in a year [2]. This plant is found in home gardens in Brazilian Amazon, being used in food and for medicinal purposes [3]. There are two varieties of Surinam Cherry: Common bright red and rare dark Crimson nearly black [4]. Brazilian Cherry or Suriname Cherry, is an outstanding source of ascorbic acid, carotenoids and phenolic compounds, mainly flavonoids, with high antioxidant activities [5,6] Epidemiological studies have shown that the consumption of fruits and vegetables imparts many health benefits, especially reduced risk of chronic diseases, such as cancer, cardiovascular disease and stroke [7] and their antioxidant activities are directly related to slowing of the ageing process [8] and the prevention of diseases such as cancer [9]. Therefore, Brazilian Cherry is a promising fruit and its pulp production has economic potential because the product has both consumer appeal and a high concentration of antioxidant compounds, such as anthocyanins, flavonols and carotenoids [9]. Polyphenolic compounds such as flavonoids also contribute to the beneficial effects of Brazilian Cherry fruits [11]. Carotenoids are known to have various biological functions such as vitamin A activity and Prevention of cataract, age related macular degeneration, cancer and cardiovascular diseases [12, 13, 14, 15]. There are also some other health benefits of Brazilian Cherry or Surinam Cherry. Vitamin C is an essential nutrient that is found in a variety of fruits and vegetables particularly in citrus fruits and this vitamin is a crucial participant in the army of immunity. It helps prevent the common cold. As we know, eating a diet rich in Vitamin C can help boost our immune system and protect our cells against damage. Vitamin $\mathrm{C}$ also known as ascorbic acid, is a water-soluble vitamin that is involved in many bodily functions, including the formation and maintenance of bones, skin and blood vessels. This essential vitamin also promotes wound healing. It acts as a powerful antioxidant and protects against damage induced by oxidative stress. For severe infections, including sepsis and Acute Respiratory Distress Syndrome (ARDS), high dose intravenous vitamin $\mathrm{C}$ treatment has been shown to significantly improve symptoms in patients. Adding vitamin C-rich foods to our diet may be one of the best ways to improve our immunity, which can help to prevent and fight infections such as COVID-19. According to literature, Brazilian cherry contains much more vitamin $\mathrm{C}$ and if we can grow awareness to add this cherry fruits in our daily diet, so we can improve our immunity that may contribute to prevent and fight against infections like recent pandemic infection by COVID-19 in our country as a whole world wide. The sufficient level of vitamin C in Brazilian Cherry or Surinam Cherry helps to prevent the damage of blood vessels caused by free radicals. The studies show that high intake of vitamin $\mathrm{C}$ helps to lower the chances of mouth, throat, vocal cords, rectum, colon, and esophagus and stomach cancer. Brazilian Cherry or Surinam Cherry also contains high concentration of vitamin A as we mentioned earlier. Vitamin A helps to eradicate the body from toxins and free radicals which damages the skin. It provides soft and supple skin by retaining the moisture, prevent dryness, keratinization and skin ailments such as psoriasis. Even though different varieties of Cherry are widely cultivating in various countries and several works have been done on nutritional composition and medicinal value of Brazilian Cherry in abroad but as far we know there is no reports for the cultivation as well as nutritional, phytochemical and medicinal uses of Brazilian Cherry Fruits in Bangladesh. Based on the nutritional, medicinal, and commercial value of Brazilian Cherry found in literature, the objective of this research were to cultivate Brazilian Cheery Fruits Plants in our NSTU Campus, Bangladesh for fruits production and to determine the antioxidant activities and total phenolic content of different solvent extracts (Water, Methanol and Ethanol) of Ripe Brazilian Cherry Fruits in Red Color (BC-RC-W, BC-RC-M \& BC-RC-E) and compare those activities with non-ripe Brazilian Cherry Fruits in Green Color (BC-GC-W, BC-GC-M \& BC-GC-E).

\section{Material and methods}

In order to fulfil the objective of this research we collected mother plants from Varendra Region, Rajshahi, Bangladesh and other nurseries in Bangladesh and planted those plants in our NSTU (Noakhali Science and Technology University) Campus, Noakhali, Bangladesh and after 6 months of plantation, surprisingly these Cherry plants produced lots of flowers and within one month we found lots of Ripe Brazilian Cherry Fruits in Red Color (Figure-1) and non-ripe Brazilian Cherry Fruits in Green Color (Figure-2) that were harvested from our own cultivated Brazilian Cherry Plants. So, the experimental cultivation of Brazilian Cherry Fruits Plants as far we know for the first time in mini scale in NSTU Campus encouraged us to know detailed Nutritional, phytochemical and medicinal properties of these fruits as a result we collected both Brazilian Cherry Fruits from Brazilian Cherry Fruits Plants and brought those samples into the Laboratory of Biochemistry and Molecular Biology, Noakhali Science and Technology University, Bangladesh for further analysis. 


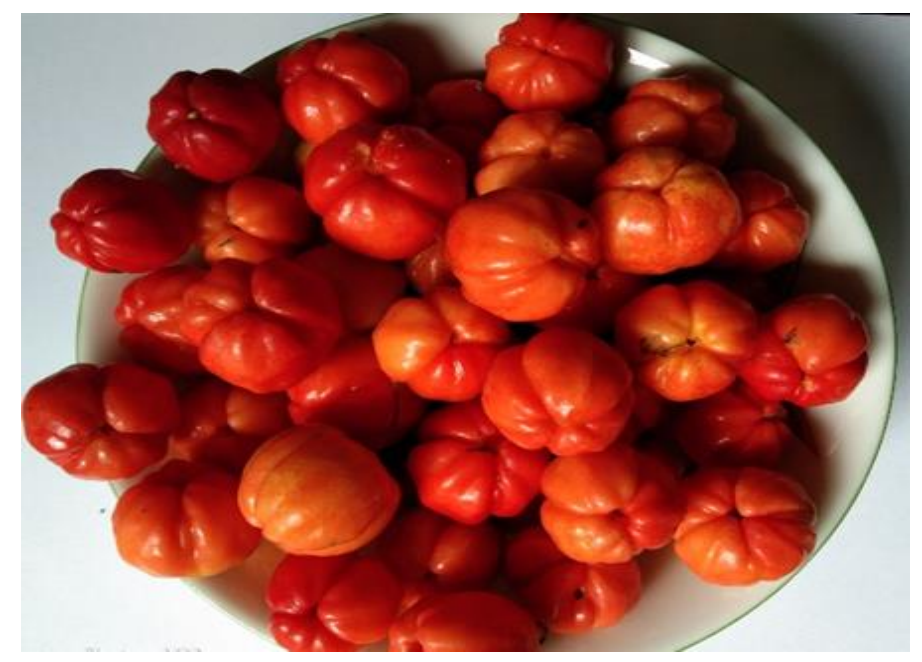

Figure 1 Ripe Brazilian Cherry fruits in Red Color (BC-RC) that harvested from our own cultivated Brazilian Cherry Fruits Plants for analysis

Source: Fruits (BC-RC) that collected from our own cultivated Brazilian Cherry Fruits Plants in NSTU Campus

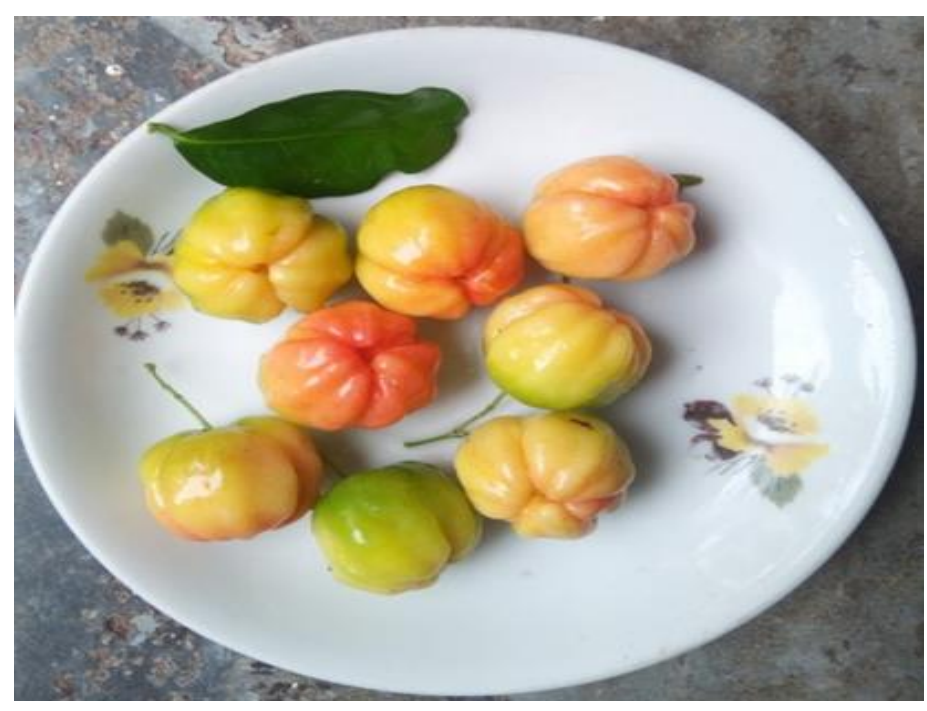

Figure 2 Non-Ripe Brazilian Cherry fruits in Green Color (BC-GC) that harvested from our own cultivated Brazilian Cherry Fruits Plants for analysis

\section{Source: Fruits (BC-GC) that collected from our own cultivated Brazilian Cherry Fruits Plants in NSTU Campus}

\subsection{Preparation of sample extracts}

The experimental sample were extracted from Ripe Brazilian Cherry Fruits in Red Color and non-ripe Brazilian Cherry Fruits in Green Color by Water, Methanol and Ethanol by a suitable laboratory method and stored these samples in Deep refrigerator for further analysis.

\subsection{Qualitative determination of antioxidant activity}

According to Kannan RR [16] with slight modification, antioxidant ingredient was analyzed by Thin Layer Chromatography (TLC) followed by DPPH (2, 2 -Diphenyl-1-picrylhydrazyl). About $10 \mu \mathrm{g}$ of Water, Methanol and Ethanol extracts of Ripe Brazilian Cherry Fruits in Red Color (BC-RC-W, BC-RC-M \& BC-RC-E) and non-ripe Brazilian Cherry Fruits in Green Color (BC-GC-W, BC-GC-M \& BC-GC-E) and $50 \mu$ g of Standard L-Ascorbic Acid, each 20 $\mu$ were loaded on TLC plate and dry at room temperature. After that $0.05 \%$ of DPPH solution in Methanol was sprayed on the 
face of TLC plate and incubated for 30 minutes at room temperature. The active antioxidant activity of Water, Methanol and Ethanol extracts of Ripe Brazilian Cherry Fruits in Red Color (BC-RC-W, BC-RC-M \& BC-RC-E) and non-ripe Brazilian Cherry Fruits in Green Color (BC-GC-W, BC-GC-M \& BC-GC-E) were detected as yellowish spots by comparing with the color activity of Standard ascorbic acid. The strength of activity for antioxidant compounds were identified by studying the change in color.

\subsection{Quantitative determination of free radical scavenging activity (DPPH method)}

The antioxidant activity of Water, Methanol and Ethanol extracts of Ripe Brazilian Cherry Fruits in Red Color (BC-RCW, BC-RC-M \& BC-RC-E) and non-ripe Brazilian Cherry Fruits in Green Color (BC-GC-W, BC-GC-M \& BC-GC-E) were measured on the basis of the scavenging activity of the stable 1,1-Diphenyl-2-picrylhydrazyl (DPPH) free radical according to the method described by Brand-Williams W [17] with slight modifications. At first $0.2 \mathrm{mM}$ DPPH solution was prepared freshly in methanol. $1.5 \mathrm{ml}$ of each extracts and standard Ascorbic acid with same concentration (100 $\mu \mathrm{g} / \mathrm{ml}$ ) was pipetted into different test tubes and the $1.5 \mathrm{ml}$ of $0.2 \mathrm{mM}$ DPPH solution was added to each sample to initiation reaction. All the samples were mixed and kept at dark for 30 minutes. After 30 minutes of incubation, the absorbance was read at wavelength at $517 \mathrm{~nm}$ by using T80 UV-VIS Spectrophotometer. Methanol was used as a blank and $0.2 \mathrm{mM}$ DPPH solution was used a control. Analysis was done in triplicate for all extracts and standard. Antioxidant activity of each extracts were determined based on the reduction of DPPH absorbance by calculating percentage of antioxidant activity by using the following formula [18].

$$
\text { Percentage (\%) of free radical DPPH scavenging }=\frac{A_{0}-A_{1}}{A_{0}} \times 100
$$

A0=Control absorbance, $\mathrm{A} 1=$ Absorbance of sample.

Final results were expressed as $\mathrm{IC}_{50}$ values, i.e. mg of ascorbic acid/100g of Brazilian Cherry Fruits needed to reduce DPPH radical by 50\%. The parameter used was $\mathrm{IC}_{50}$ means the concentration of testing compound required for scavenging $50 \%$ free radical's DPPH. The lower the IC $_{50}$ value, the stronger the antioxidant activity of the testing compound.

\subsection{Determination of Total Phenolic Content (TPC) by Folin-Ciocalteu test}

The total phenolic content of different extracts of Ripe Brazilian Cherry Fruits in Red Color (BC-RC-W, BC-RC-M \& BCRC-E) and non-ripe Brazilian Cherry Fruits in Green Color (BC-GC-W, BC-GC-M \& BC-GC-E) was determined according to the Nursyahda Zakaria [19] by Folin-Ciocalteu assay using T80 UV-VIS Spectrophotometer at $765 \mathrm{~nm}$. The total phenolic content was calculated based on a standard curve established with gallic acid as a standard (Figure-8). $0.1 \mathrm{ml}$ of each sample was mixed with $0.9 \mathrm{ml}$ of distilled water in a test tube. Then $0.05 \mathrm{ml}$ of Folin- Ciocalteu Reagent were added to each sample and mixed well for 2 minutes. Then $0.5 \mathrm{ml}$ of $5 \%$ of freshly prepared sodium carbonate solution were added to each sample followed by $2.5 \mathrm{ml}$ of distilled water and mixed well. All the mixtures were incubating in dark for an hour and after one hour absorbance of all samples were read at $765 \mathrm{~nm}$ by T80 UV-VIS Spectrophotometer. The total phenolic contents were expressed in gallic acid equivalents (mg per 100 gram fresh fruits). The gallic acid standard line has the equation $\mathrm{y}=0.0066 \mathrm{x}+0.0159(\mathrm{R} 2=0.999)$, where $\mathrm{y}$ is absorbance at $765 \mathrm{~nm}$ and $\mathrm{x}$ is the concentration of gallic acid in $\mathrm{mg} / \mathrm{L}$. According to [20], the total content of phenolic compounds in the extract in Gallic Acid Equivalents (GAE) was calculated by the following formula:

$$
T=\frac{C \times V}{M}
$$

Where, $\mathrm{T}=$ Total content of phenolic compounds, milligram per gram fruit extract, in GAE, $\mathrm{C}=$ the concentration of gallic acid established from the calibration curve, milligram per milliliter, $\mathrm{V}=$ the volume of extract, milliliter, $\mathrm{M}=$ the weight of fruit extract in gram.

\section{Results and discussion}

\subsection{Qualitative Determination of Antioxidant activity}

In TLC method the spots on layer determine the activity of Antioxidant activity of Water, Methanol and Ethanol extracts of Ripe Brazilian Cherry Fruits in Red Color (BC-RC-W, BC-RC-M \& BC-RC-E) and non-ripe Brazilian Cherry Fruits in Green Color (BC-GC-W, BC-GC-M \& BC-GC-E) as compared with standard L-ascorbic acid, the Figure-3 shows that the 
Brazilian Cherry Fruits in both Color stage have a good activity against DPPH compound; this result also indicated that all extracts of Brazilian Cherry Fruits contain high antioxidant compounds.

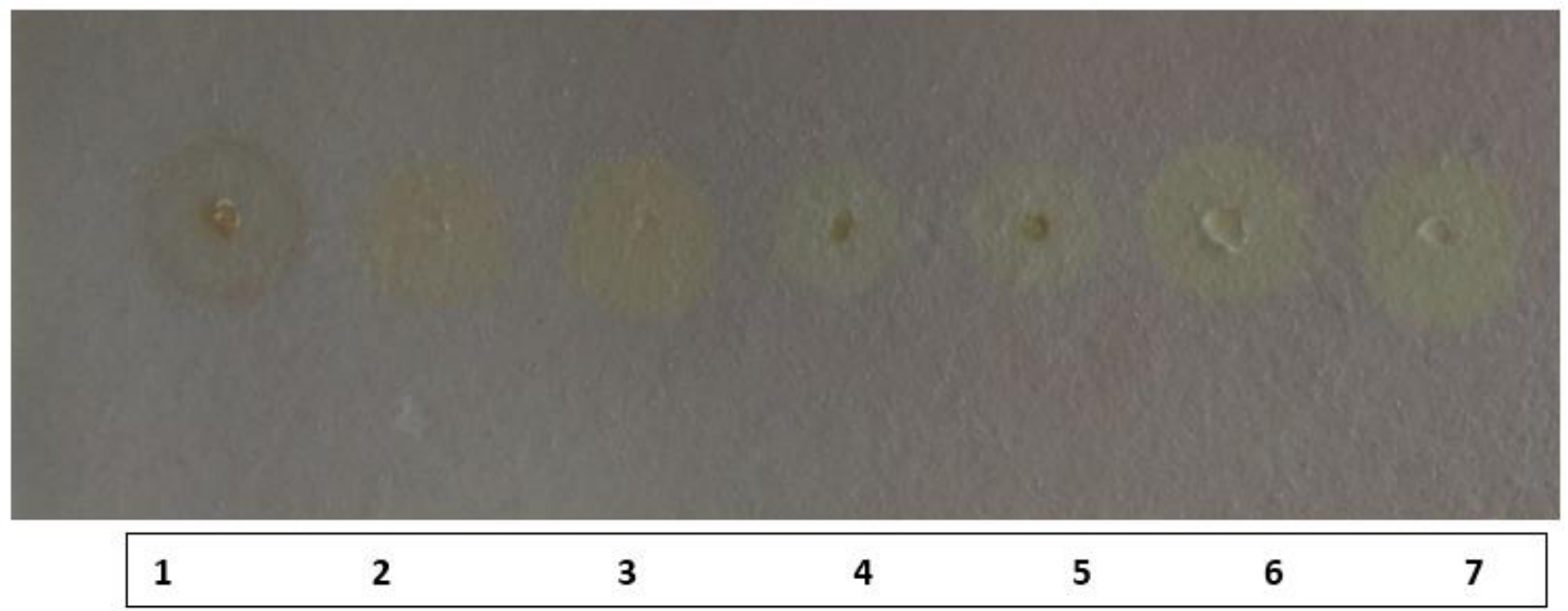

Lane-1: BC-RC-WE, Lane-2: BC-RC-ME, Lane-3: BC-RC-EE, Lane-4: BC-GC-WE, Lane-5: BC-GC-ME, Lane-6: BC-GC-EE, Lane-7: L-Ascorbic Acid as Standard

Figure 3 Antioxidant activity of Water, Methanol and Ethanol extracts of Ripe Brazilian Cherry Fruits in Red Color (BCRC-W, BC-RC-M \& BC-RC-E) and non-ripe Brazilian Cherry Fruits in Green Color (BC-GC-W, BC-GC-M \& BC-GC-E) with Ascorbic Acid as a standard by DPPH method in TLC plate.

\subsection{Antioxidant activities of different solvent extracts of Ripe Brazilian Cherry Fruits in Red Color and non- ripe Brazilian Cherry Fruits in Green Color by DPPH assays}

Antioxidant activities of Water, Methanol and Ethanol extracts of Ripe Brazilian Cherry Fruits in Red Color (BC-RC-W, BC-RC-M \& BC-RC-E) and non-ripe Brazilian Cherry Fruits in Green Color (BC-GC-W, BC-GC-M \& BC-GC-E) by DPPH method that were shown in Table-1, Table- 2 and Table- 3 and the results were summarized in Figure-4, 5. In the present study, all the extracts exhibited DPPH radical scavenging activity and the range of antioxidant activities of Water, Methanol and Ethanol extracts of Ripe Brazilian Cherry Fruits in Red Color (BC-RC-W, BC-RC-M \& BC-RC-E) and nonripe Brazilian Cherry Fruits in Green Color (BC-GC-W, BC-GC-M \& BC-GC-E) were found to be 50.20-73.66\% by comparing the activity (97.65\%) exhibited with a standard ascorbic acid in a constant concentration (Table-1,2,3).

Among all extracts, in both Ripe and Non-Ripe Brazilian Cherry Fruits, the Water extract of non-ripe Brazilian Cherry Fruits (BC-GC-W) had the highest DPPH radical scavenging activity or capacity (73.66\%) followed by Ethanol extract of Ripe-Brazilian Cheery Fruits (BC-RC-E) (59.92\%), Methanol extract of Ripe-Brazilian Cheery Fruits(BC-RC-M) (57.47\%), Methanol extract of Non-Ripe Brazilian Cherry Fruits (BC-GC-M)(55.58\%) and Ethanol extract of RipeBrazilian Cheery Fruits (BC-RC-E) (54.09\%), on the other hand, the lowest antioxidant activity of Water extract of RipeBrazilian Cheery Fruits(BC-RC-W) (50.20\%) (Table-1, 2, 3 and Figure-4, 5).

Table 1 DPPH radical scavenging activity of Water extract of Ripe Brazilian Cherry Fruits in Red Color (BC-RC-W) and non-ripe Brazilian Cherry Fruits in Green Color (BC-GC-W) and Ascorbic Acid

\begin{tabular}{|c|c|c|c|c|c|c|c|}
\hline \multirow[t]{2}{*}{ Sr. no. } & \multirow[t]{2}{*}{$\begin{array}{l}\text { Sample } \\
\text { Name }\end{array}$} & \multirow[t]{2}{*}{$\begin{array}{l}\text { Concentration } \\
(\mu \mathrm{g} / \mathrm{ml})\end{array}$} & \multicolumn{3}{|c|}{$\begin{array}{l}\% \text { of DPPH Scavenging } \\
\text { Activity }\end{array}$} & \multirow[t]{2}{*}{ Mean \pm SD } & \multirow[t]{2}{*}{$\mathrm{IC}_{50}(\mu \mathrm{g} / \mathrm{ml})$} \\
\hline & & & A & B & C & & \\
\hline 1 & BC-RC-W & 100 & 50.17 & 50.25 & 50.19 & $50.20 \pm 0.04$ & 1.24 \\
\hline 2 & BC-GC-W & 100 & 73.50 & 74.01 & 73.66 & $73.66 \pm 0.30$ & 1.01 \\
\hline 3 & Ascorbic Acid & 100 & 97.65 & 97.68 & 97.63 & $97.65 \pm 0.02$ & 0.84 \\
\hline
\end{tabular}


Table 2 DPPH radical scavenging activity of Water extract of Ripe Brazilian Cherry fruits in Red Color (BC-RC-M) and non-ripe Brazilian Cherry Fruits in Green Color (BC-GC-M) and Ascorbic Acid

\begin{tabular}{|c|c|c|c|c|c|c|c|}
\hline \multirow[t]{2}{*}{$\begin{array}{l}\text { Sr. } \\
\text { No. }\end{array}$} & \multirow[t]{2}{*}{$\begin{array}{l}\text { Sample } \\
\text { Name }\end{array}$} & \multirow[t]{2}{*}{$\begin{array}{l}\text { Concentration } \\
(\mu \mathrm{g} / \mathrm{ml})\end{array}$} & \multicolumn{3}{|c|}{$\begin{array}{l}\text { \% of DPPH Scavenging } \\
\text { Activity }\end{array}$} & \multirow[t]{2}{*}{ Mean \pm SD } & \multirow[t]{2}{*}{$\mathrm{IC}_{50}(\mu \mathrm{g} / \mathrm{ml})$} \\
\hline & & & A & B & C & & \\
\hline 1 & BC-RC-M & 100 & 57.47 & 57.50 & 57.45 & $57.47 \pm 0.02$ & 1.16 \\
\hline 2 & BC-GC-M & 100 & 55.25 & 56.12 & 55.38 & $55.58 \pm 0.46$ & 1.18 \\
\hline 3 & Ascorbic Acid & 100 & 97.65 & 97.68 & 97.63 & $97.65 \pm 0.02$ & 0.84 \\
\hline
\end{tabular}

Table 3 DPPH radical scavenging activity of Water extract of Ripe Brazilian Cherry Fruits in Red Color (BC-RC-E) and non-ripe Brazilian Cherry Fruits in Green Color (BC-GC-E) and Ascorbic Acid

\begin{tabular}{|c|c|c|c|c|c|c|c|}
\hline \multirow[t]{2}{*}{ Sr. No. } & \multirow[t]{2}{*}{$\begin{array}{l}\text { Sample } \\
\text { Name }\end{array}$} & \multirow[t]{2}{*}{$\begin{array}{l}\text { Concentration } \\
(\mu \mathrm{g} / \mathrm{ml})\end{array}$} & \multicolumn{3}{|c|}{$\begin{array}{l}\% \text { of DPPH Scavenging } \\
\text { Activity }\end{array}$} & \multirow[t]{2}{*}{ Mean \pm SD } & \multirow[t]{2}{*}{$\mathrm{IC}_{50}(\mu \mathrm{g} / \mathrm{ml})$} \\
\hline & & & A & B & C & & \\
\hline 1 & BC-RC-E & 100 & 53.98 & 54.21 & 54.10 & $54.09 \pm 11$ & 1.20 \\
\hline 2 & BC-GC-E & 100 & 59.74 & 59.82 & 60.20 & $59.92 \pm 0.24$ & 1.13 \\
\hline 3 & $\begin{array}{l}\text { Ascorbic } \\
\text { Acid }\end{array}$ & 100 & 97.65 & 97.68 & 97.63 & $97.65 \pm 0.02$ & 0.84 \\
\hline
\end{tabular}

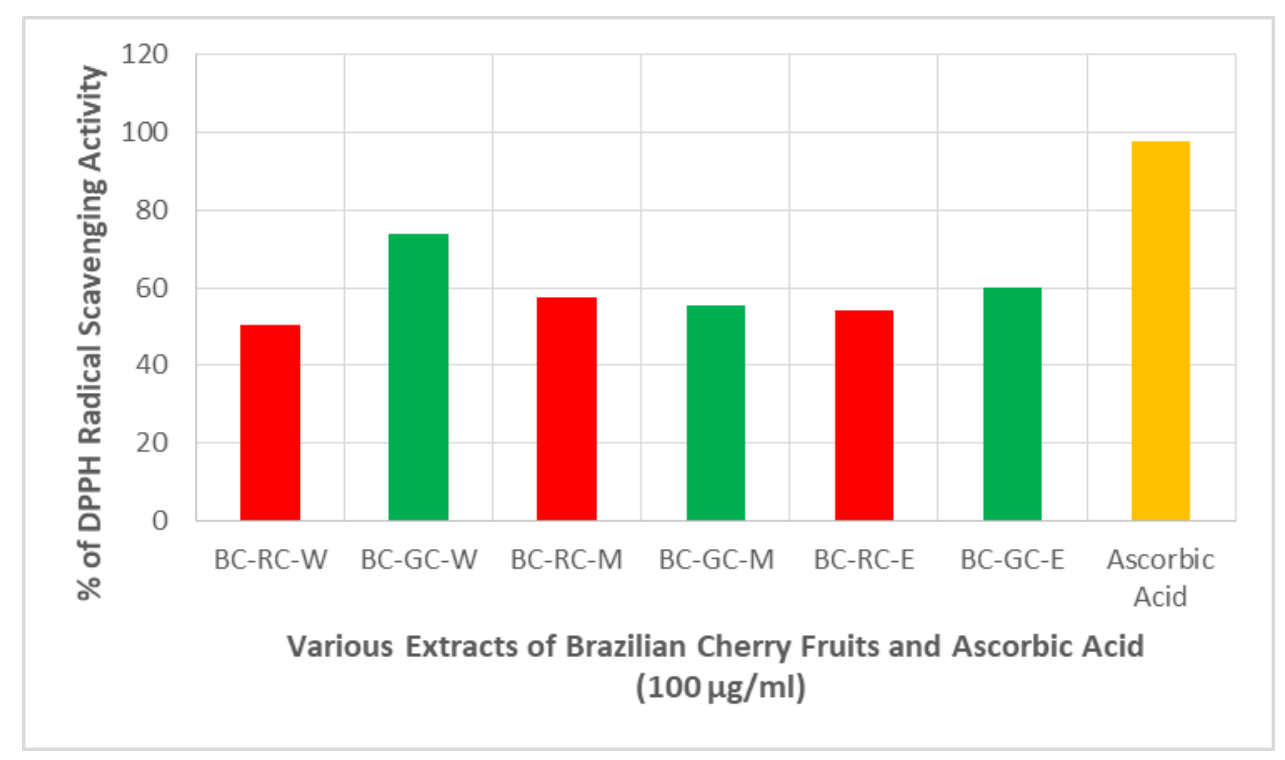

Figure 4 DPPH scavenging activity of different solvent extracts of Ripe Brazilian Cherry Fruits in Red Color (BC-RC-W, BC-RC-M \& BC-RC-E) and non-ripe Brazilian Cherry Fruits in Green Color (BC-GC-W, BC-GC-M \& BC-GC-E), respectively. 


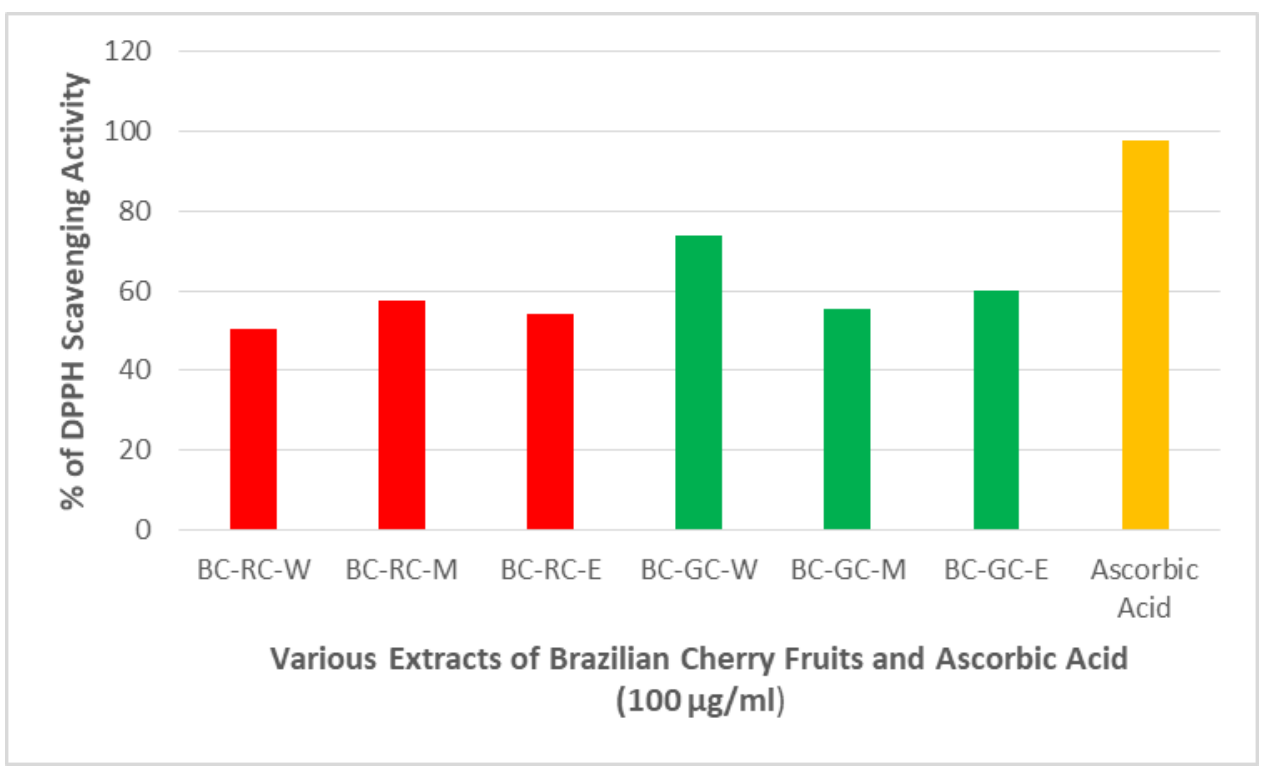

Figure 5 DPPH scavenging activity of different solvent extracts of Ripe Brazilian Cherry Fruits in Red Color (BC-RC-W, BC-RC-M \& BC-RC-E) and non-ripe Brazilian Cherry Fruits in Green Color (BC-GC-W, BC-GC-M \& BC-GC-E), respectively.

\subsection{IC $\mathrm{C}_{50}$ of DPPH scavenging capacities}

IC $5_{50}$ of DPPH scavenging capacities of Water, Methanol and Ethanol extracts of Ripe Brazilian Cherry Fruits in Red Color (BC-RC-W, BC-RC-M \& BC-RC-E) and non-ripe Brazilian Cherry Fruits in Green Color (BC-GC-W, BC-GC-M \& BC-GC-E) including ascorbic acid by DPPH method were shown in Table-1, Table- 2 and Table-3 and the results were summarized in Figure-6.7. The IC 50 of DPPH scavenging activities of each extracts were compared to ascorbic acid as standard. The lowest $\mathrm{IC}_{50}$ means had the highest antioxidant capacity. Concentration of sample that could scavenge $50 \%$ free radical ( $\mathrm{IC}_{50}$ ) was used to determined antioxidant capacity of sample compared to standard that had $\mathrm{IC}_{50}$ less than $50 \mathrm{ppm}$, it was very strong antioxidant activity, $50-100 \mathrm{ppm}$ strong antioxidant activity, 101-150 ppm will be medium antioxidant activity, while $\mathrm{IC}_{50}$ is greater than $150 \mathrm{ppm}$ it will be lowest antioxidant activity [21].

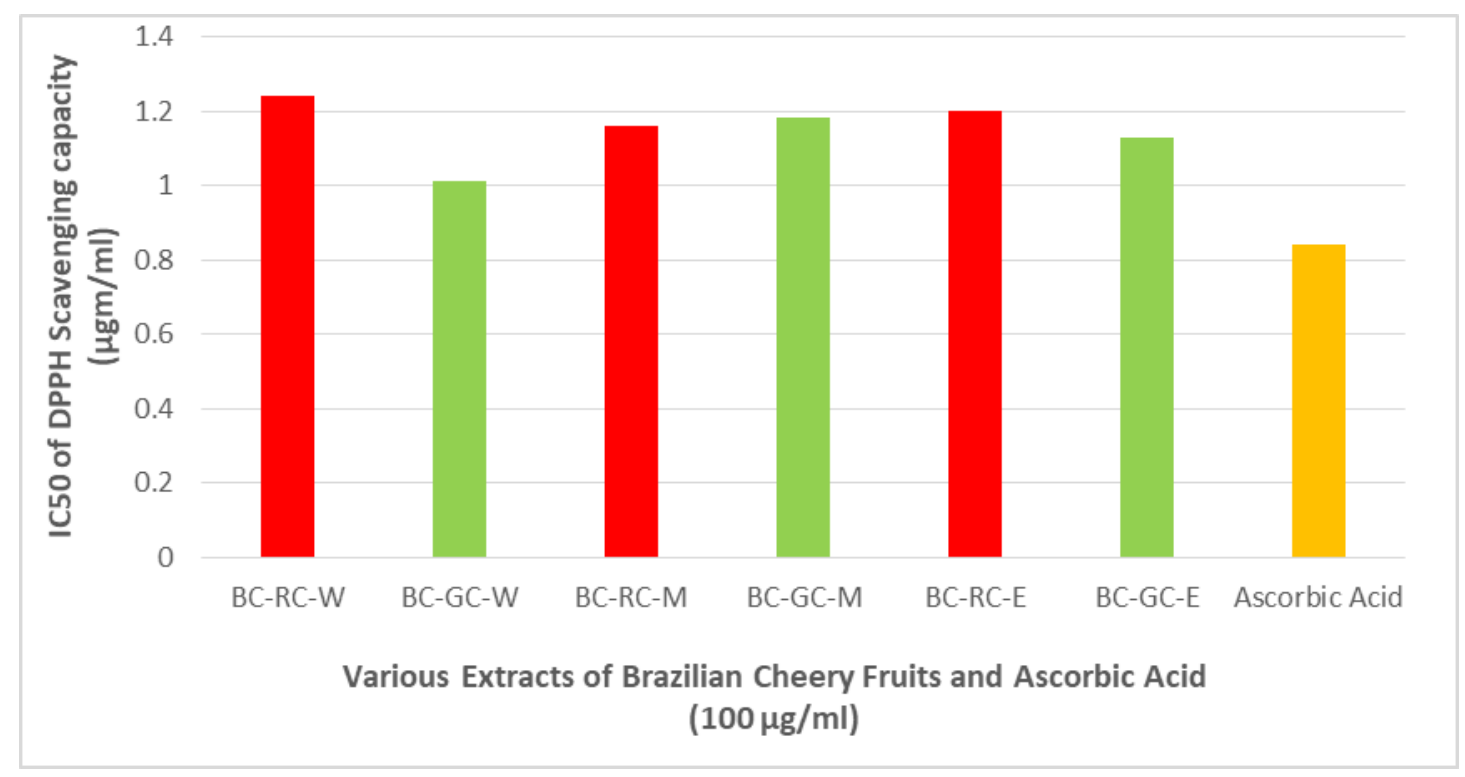

Figure 6 IC $_{50}$ of DPPH scavenging capacities of different solvent extracts of Ripe Brazilian Cherry Fruits in Red Color (BC-RC-W, BC-RC-M \& BC-RC-E) and non-ripe Brazilian Cherry Fruits in Green Color (BC-GC-W, BC-GC-M \& BC-GC-E), respectively 


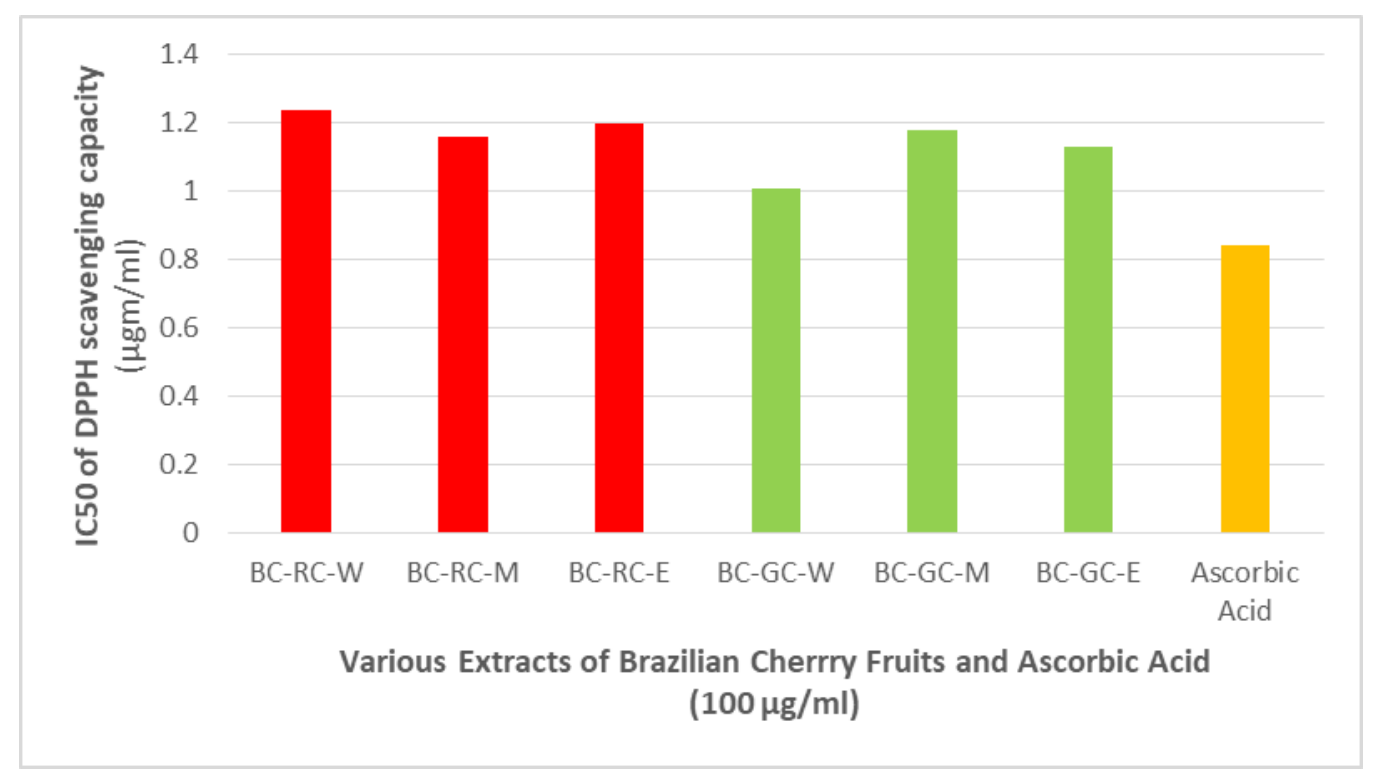

Figure 7 IC 50 of DPPH scavenging capacities of different solvent extracts of Ripe Brazilian Cherry Fruits in Red Color (BC-RC-W, BC-RC-M \& BC-RC-E) and non-ripe Brazilian Cherry Fruits in Green Color (BC-GC-W, BC-GC-M \& BC-GC-E), respectively.

In the present study, all the extracts of Ripe Brazilian Cherry Fruits in Red Color (BC-RC-W, BC-RC-M \& BC-RC-E) and non-ripe Brazilian Cherry Fruits in Green Color (BC-GC-W, BC-GC-M \& BC-GC-E) had the IC50 of DPPH scavenging activities in the range of $1.01 \mu \mathrm{g} / \mathrm{ml}$ to $1.24 \mu / \mathrm{ml}$ and the IC $_{50}$ of DPPH scavenging activity of a standard ascorbic acid was found to be $0.84 \mu \mathrm{g} / \mathrm{ml}$ (Table-1,2,3 and Figure-6,7). Based on the classification of antioxidant potency [21], all the extracts sample of Ripe Brazilian Cherry Fruits in Red Color (BC-RC-W, BC-RC-M \& BC-RC-E) and non-ripe Brazilian Cherry Fruits in Green Color (BC-GC-W, BC-GC-M \& BC-GC-E) can be classified as very strong antioxidant activity. Among all extracts of both Ripe Brazilian Cherry Fruits in Red Color (BC-RC-W, BC-RC-M \& BC-RC-E) and non-ripe Brazilian Cherry Fruits in Green Color (BC-GC-W, BC-GC-M \& BC-GC-E), the Water extract of non-ripe Brazilian Cherry Fruits in Green Color (BC-GC-W) had the lowest IC 50 of DPPH scavenging activity $(1.01 \mu \mathrm{g} / \mathrm{ml})$ which is very close to the $\mathrm{IC}_{50}$ DPPH scavenging activity of ascorbic acid as standard $(0.84 \mu \mathrm{g} / \mathrm{ml})$. The $\mathrm{IC}_{50}$ DPPH scavenging activity of Methanol extract of both of both Ripe Brazilian Cherry Fruits in Red Color and non-ripe Brazilian Cherry Fruits in Green Color (BC-RC-M, BC-RC-M) and Ethanol extract of Ripe Brazilian Cherry Fruits in Red Color (BC-RC-E) were found to be very close i.e. $1.16 \mu \mathrm{g} / \mathrm{ml}, 1.18 \mu \mathrm{g} / \mathrm{ml}$, and $1.20 \mu \mathrm{g} / \mathrm{ml}$, respectively (Fig.6, 7).The second lowest IC So $_{0}$ DPPH scavenging activity of Ethanol extract of Ripe Brazilian Cherry Fruits in Red Color (BC-RC-E) $1.13 \mu \mathrm{g} / \mathrm{ml}$ and the highest IC 50 DPPH scavenging activity of Water extract of Ripe Brazilian Cherry Fruits in Red Color (BC-RC-W) was found to be $1.24 \mu \mathrm{g} / \mathrm{ml}$ (Table-1,2,3 and Figure-6,7).

\subsection{Total Phenolic content}

Table- 5 and Table- 6 showed the total Phenolic content of Water, Methanol and Ethanol extracts of Ripe Brazilian Cherry Fruits in Red Color (BC-RC-W, BC-RC-M \& BC-RC-E) and non-ripe Brazilian Cherry Fruits in Green Color (BC-GC-W, BCGC-M \& BC-GC-E), respectively and it was presented as a summary in Figure-9.

The total Phenolic content of Water, Methanol and Ethanol extracts of Ripe Brazilian Cherry Fruits in Red Color (BC-RCW, BC-RC-M \& BC-RC-E) and non-ripe Brazilian Cherry Fruits in Green Color (BC-GC-W, BC-GC-M \& BC-GC-E) were found to be in the range of $106.004 \mathrm{mg} \mathrm{GAE} / 100 \mathrm{gm}$ to $111.52 \mathrm{mg} \mathrm{GAE} / 100 \mathrm{gm}$ which is lower than the phenolic content of Red-fleshed pitanga (Eugenia uniflora L.) ( $210 \pm 3$ ) that cultivated in the Rio Grande do Sul as reported by [22], but higher than that of orange $(75 \pm 10 \mathrm{mg}$ gallic acid equivalent $/ 100 \mathrm{~g})$ and banana $(51 \pm 7 \mathrm{mg}$ gallic acid equivalent $/ 100 \mathrm{~g}$ ) as reported by[23]. Among the all extracts of Ripe Brazilian Cherry Fruits in Red Color (BC-RC-W, BC-RC-M \& BC-RC-E) and non-ripe Brazilian Cherry fruits in Green Color (BC-GC-W, BC-GC-M \& BC-GC-E), the Methanol extracts of non-ripe Brazilian Cherry Fruits in Green Color (BC-GC-M) was found to be highest total phenolic content $111.52 \mathrm{mg}$ gallic acid equivalent/100g, and the Ethanol extracts of Ripe Brazilian Cherry Fruits in Red Color (BC-RC-E) was found to be lowest total phenolic content, $106.004 \mathrm{mg}$ gallic acid equivalent/100g (Table-5, 6 and Figure-6).The total phenolic content of Water and Methanol extracts of Ripe Brazilian Cherry Fruits in Red Color (BC-RC-W \& BC-RC-M ) was found very similar, i.e. (109.894, and $109.642 \mathrm{mg}$ gallic acid equivalent/100g, respectively) and it was also found that the total phenolic 
content of the Water and Ethanol extracts of non-Ripe Brazilian Cherry Fruits in Green Color (BC-GC-W \& BC-GC-E ) and Ethanol extract of Ripe Brazilian Cherry Fruits in Red Color (BC-RC-E) was found very similar i.e. 106.156, 106.004, and $107.156 \mathrm{mg}$ gallic acid equivalent/100g, respectively (Table-5, 6 and Figure-9). The phenolic compounds influence the fruit quality contributing both to their sensory and health-promoting properties [24]. From this result it is found that the Brazilian Cherry Fruits are rich source of antioxidant compounds and total phenolic compounds that may help to increase the immunity of our body to prevent infections and allows a person to recover faster from any illness and also prevent stroke, heart attack and various diseases including different types of cancer. The antioxidant and phenolic compounds like vitamin C may also regenerates the damaged skin tissues and builds collagen, which helps in maintaining the youthfulness of the skin and prevents wrinkles, fine lines and stretch marks and also prevent different types of cancer. Even though total phenolic content present in Methanol extracts of non-Ripe Brazilian Cherry Fruits in Green Color (BC-GC-M ) was found to be higher (111.52 mg gallic acid equivalent/100g) among all extracts, but the antioxidant activity is highest (73.66\%) in Water extract of non-Ripe Brazilian Cherry Fruits in Green Color (BC-GC-W) based on the $\mathrm{IC}_{50}$ of DPPH scavenging activity $(1.01 \mu \mathrm{g} / \mathrm{ml})$.This may be due to the presence of vitamin $\mathrm{C}$ which is almost double in green or unripe fruits the ripe fruits in red Color as reported in the website[25].

Table 4 Absorbance of gallic acid (as standard) at different concentrations

\begin{tabular}{|c|c|c|c|c|}
\hline \multirow{2}{*}{ Conc. $(\boldsymbol{\mu g} / \mathbf{m l})$} & \multicolumn{3}{|c|}{ Absorbance at 765 nm } & \multirow{2}{*}{ Mean \pm SD } \\
\cline { 2 - 4 } & $\mathrm{A}$ & $\mathrm{B}$ & $\mathrm{C}$ & \\
\hline 0 & 0 & 0 & 0 & 0 \\
\hline 50 & 0.349 & 0.348 & 0.345 & $0.347 \pm 0.002$ \\
\hline 100 & 0.701 & 0.704 & 0.706 & $0.703 \pm 0.002$ \\
\hline 150 & 0.989 & 0.978 & 0.981 & $0.982 \pm 0.005$ \\
\hline 200 & 1.342 & 1.334 & 1.347 & $1.341 \pm 0.006$ \\
\hline 250 & 1.646 & 1.648 & 1.641 & $1.645 \pm 0.003$ \\
\hline
\end{tabular}

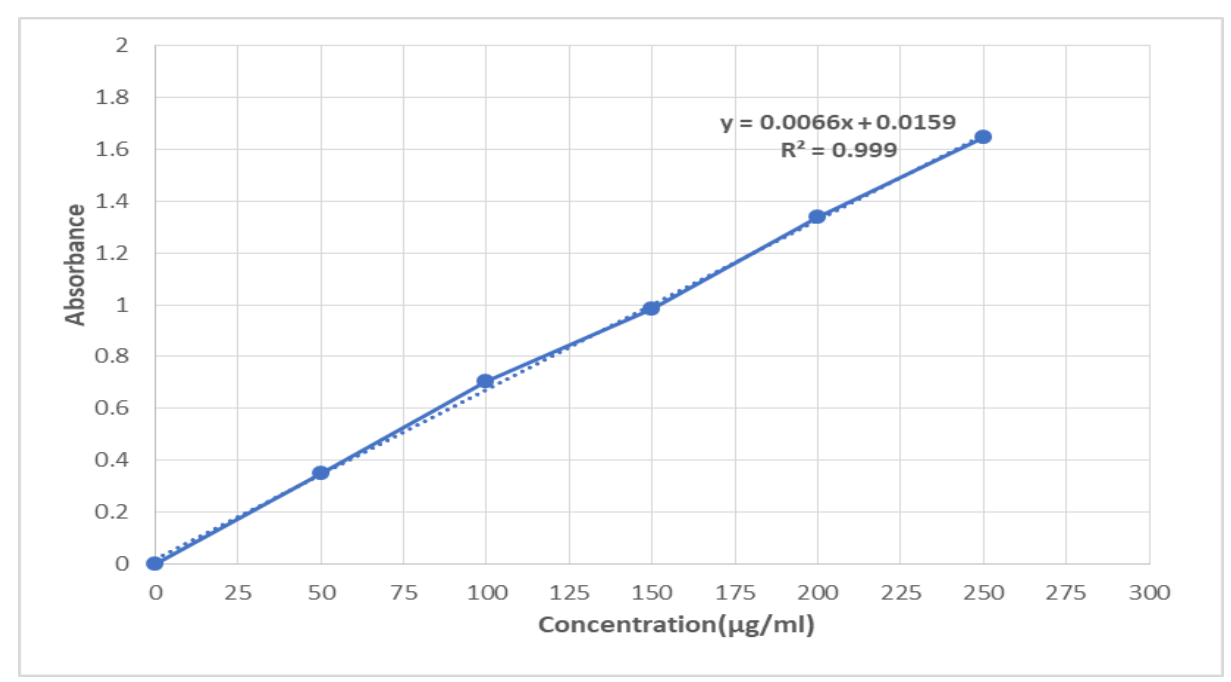

Figure 8 Standard curve of gallic acid for the determination of Total Phenolic Content (TPC) 
Table 5 Total Phenolic content of Water, Methanol and Ethanol extracts of Ripe Brazilian Cherry Fruits in Red Color (BC-RC-W, BC-RC-M \& BC-RC-E), respectively

\begin{tabular}{|c|c|c|c|c|c|c|c|c|}
\hline Species & $\begin{array}{l}\text { Sample } \\
\text { Name }\end{array}$ & $\begin{array}{l}\text { Type of } \\
\text { Solvent }\end{array}$ & $\begin{array}{l}\text { Con. Of } \\
\text { Sample }\end{array}$ & $\begin{array}{c}\text { No. of } \\
\text { Sample }\end{array}$ & $\begin{array}{l}\text { Abs. in } \\
765 \mathrm{~nm}\end{array}$ & Mean \pm SD & $\begin{array}{l}\text { Conc. from } \\
\text { Std curve }\end{array}$ & TPC (g/100g) \\
\hline \multirow{3}{*}{$\begin{array}{l}\text { Ripe Brazilian } \\
\text { Cherry Fruits } \\
\text { in Red Color }\end{array}$} & BC-RC-W-1 & Water & $\begin{array}{c}200 \\
\mathrm{mg} / \mathrm{ml}\end{array}$ & 1 & 1.818 & $1.824 \pm 0.006$ & $274.45 \pm 0.57$ & $219.788 \pm 0.322$ \\
\hline & BC-RC-W-2 & & & 2 & 1.831 & & & \\
\hline & BC-RC-W-3 & & & 3 & 1.823 & & & \\
\hline \multirow[t]{3}{*}{$\begin{array}{l}\text { Ripe Brazilian } \\
\text { Cherry Fruits } \\
\text { in Red Color }\end{array}$} & BC-RC-M-1 & Methanol & $\begin{array}{c}200 \\
\mathrm{mg} / \mathrm{ml}\end{array}$ & 1 & 1.829 & $1.825 \pm 0.003$ & $274.105 \pm 0.64$ & $219.796 \pm 0.724$ \\
\hline & BC-RC-M-2 & & & 2 & 1.823 & & & \\
\hline & BC-RC-M-3 & & & 3 & 1.825 & & & \\
\hline \multirow[t]{3}{*}{$\begin{array}{l}\text { Ripe Brazilian } \\
\text { Cherry Fruits } \\
\text { in Red Color }\end{array}$} & BC-RC-E-1 & Ethanol & $\begin{array}{c}200 \\
\mathrm{mg} / \mathrm{ml}\end{array}$ & 1 & 1.819 & $1.784 \pm 0.061$ & $267.89 \pm 13.06$ & $214.312 \pm 14.775$ \\
\hline & BC-RC-E-2 & & & 2 & 1.713 & & & \\
\hline & BC-RC-E-3 & & & 3 & 1.821 & & & \\
\hline
\end{tabular}

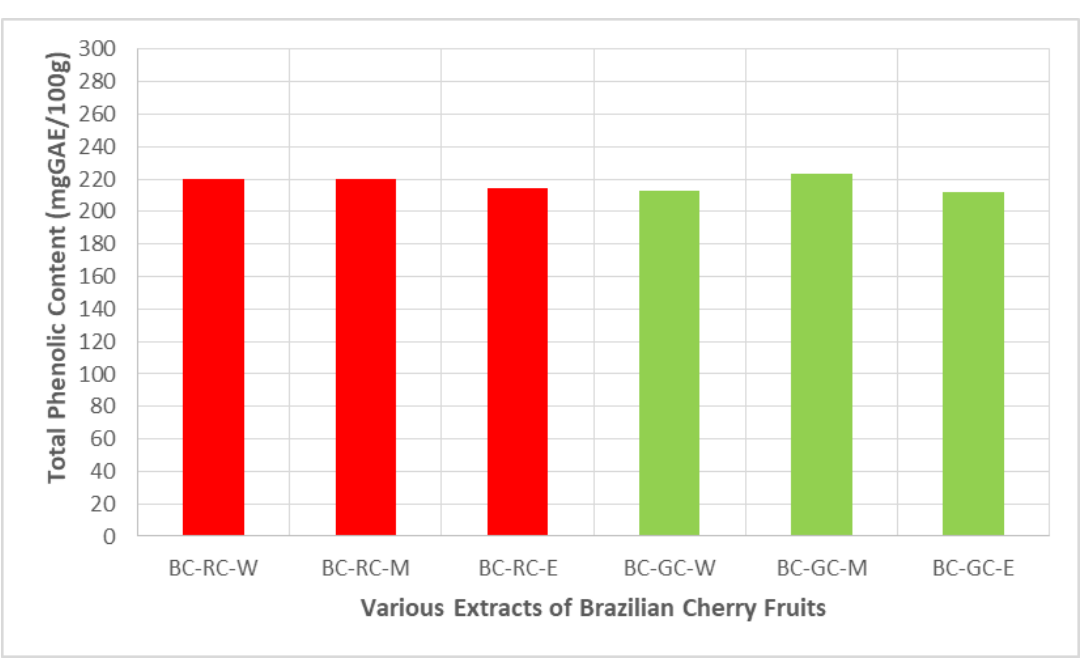

Figure 9 Total Phenolic content of Water, Methanol and Ethanol extracts of Ripe Brazilian Cherry Fruits in Red Color (BC-RC-W, BC-RC-M \& BC-RC-E) and non-ripe Brazilian Cherry Fruits in Green Color (BC-GC-W, BC-GC-M \& BC-GC-E), respectively 
Table 6 Total Phenolic content of Water, Methanol and Ethanol extracts of Ripe Brazilian Cherry Fruits in non-ripe Brazilian Cherry Fruits in Green Color (BC-GC-W, BC-GC-M \& BC-GC-E), respectively

\begin{tabular}{|c|c|c|c|c|c|c|c|c|}
\hline Species & $\begin{array}{l}\text { Sample } \\
\text { Name }\end{array}$ & $\begin{array}{l}\text { Type of } \\
\text { Solvent }\end{array}$ & $\begin{array}{l}\text { Conc. of } \\
\text { Sample }\end{array}$ & \begin{tabular}{|c} 
No of \\
Sample
\end{tabular} & $\begin{array}{l}\text { Abs in } \\
765 \mathrm{~nm}\end{array}$ & Mean \pm SD & $\begin{array}{l}\text { Conc. from } \\
\text { Std curve }\end{array}$ & TPC(g/100g) \\
\hline \multirow{4}{*}{$\begin{array}{l}\text { Non-Ripe } \\
\text { Brazilian } \\
\text { Cherry } \\
\text { Fruits } \\
\text { in Green } \\
\text { Color }\end{array}$} & BC-GC-W-1 & Water & $200 \mathrm{mg} / \mathrm{ml}$ & 1 & 1.769 & $1.766 \pm 0.002$ & $265.39 \pm 0.74$ & $212.904 \pm 0.837$ \\
\hline & BC-GC-W-2 & & & 2 & 1.764 & & & \\
\hline & BC-GC-W-3 & & & 3 & 1.767 & & & \\
\hline & & & & & & & & \\
\hline \multirow[t]{3}{*}{$\begin{array}{l}\text { Non-Ripe } \\
\text { Brazilian } \\
\text { Cherry } \\
\text { Fruits } \\
\text { in Green } \\
\text { Color } \\
\end{array}$} & BC-GC-M-1 & Methanol & $200 \mathrm{mg} / \mathrm{ml}$ & 1 & 1.854 & $1.856 \pm 0.002$ & $278.8 \pm 0.42$ & $223.04 \pm 0.475$ \\
\hline & BC-GC-M-2 & & & 2 & 1.858 & & & \\
\hline & BC-GC-M-3 & & & 3 & 1.857 & & & \\
\hline \multirow{3}{*}{$\begin{array}{l}\text { Non-Ripe } \\
\text { Brazilian } \\
\text { Cherry } \\
\text { Fruits in } \\
\text { green Color } \\
\end{array}$} & BC-GC-E-1 & Ethanol & $200 \mathrm{mg} / \mathrm{ml}$ & 1 & 1.766 & $1.765 \pm 0.001$ & $265.01 \pm 0.21$ & $212.008 \pm 0.237$ \\
\hline & BC-GC-E-2 & & & 2 & 1.774 & & & \\
\hline & BC-GC-E-3 & & & 3 & 1.767 & & & \\
\hline
\end{tabular}

\section{Conclusion}

In this research work, we cultivate Brazilian Cheery Fruits Plants at the first time in our Noakhali Science and Technology University Campus, Bangladesh for its fruits production in order to determine the antioxidant activities and total phenolic content of different solvent extracts (Water, Methanol and Ethanol ) of Ripe Brazilian Cherry Fruits in Red Color and compare those activities with non-ripe Brazilian Cherry fruits in Green Color. The results showed that all the extracts of Ripe and Non-Ripe Brazilian Cherry Fruits both in Red Color and Green Color are a good source for antioxidant ability and phenolic compounds, but among the analyzed fruits of all extracts, in both Ripe and Non-Ripe, the Water extract of non-ripe Brazilian Cherry Fruits (BC-GC-W) is the good source for strong antioxidant ability $(73.66 \%)$ and it showed the lowest IC 50 of DPPH scavenging activity $(1.01 \mu \mathrm{g} / \mathrm{ml})$ which may be due to the presence of high content of vitamin C. Thus from this results it can be concluded that Brazilian Cheery Fruits in both Ripe and NonRipe stage will be useful as an additive in food and pharmaceutical industries to prevent oxidative damage and also to prevent and fight against infection recently caused by COVID-19 in worldwide and other infectious diseases by increasing our body immunity in the long term by including this fruits in our diet chart and this fruits also will be useful as a raw material in the pharmaceutical and food industries to prepare drugs and food products.

\section{Compliance with ethical standards}

\section{Acknowledgments}

This research project was supported by a grant from the Ministry of Science and Technology, Government of the People's Republic of Bangladesh, Bangladesh Secretariat, Dhaka-1000 and we are grateful to the Ministry of Science and Technology, Government of the People's Republic of Bangladesh to provide this grant. We express heartfelt gratitude to Professor Dr. Md. Didar-ul-Alam, Vice-Chancellor, Noakhali Science and Technology University, Noakhali-3814, Bangladesh for his encouragement in this research and providing laboratory facilities for this research. 


\section{Disclosure of conflict of interest}

The authors declare that there is no conflict of interest regarding the main research, authorship and publication of this paper.

\section{References}

[1] Consolini AE, Sarubbio MG. Pharmacological effects of Eugenia uniflora (Myrtaceae) aqueous crude extract on rat's heart. J Ethnopharmacology. 2002; 81(1): 57 -63.

[2] Adams, WF Taste a Curious Crop. Advertiser Food Editor. www.adams@honoluluadvertiser.com.Accessed Feb. 28, 2007.

[3] Lunz AMP. Quintais agro florestals e o cultivo de species frutiferas na Amazonia. Rev Brasileira Agroecologia. 2007; 2(2): 1255-1258.

[4] Morton J, Julia F. Morton, Miami FL. Surinam Cherry. p. 1987; 386 - 388.

[5] Hoffmann Ribani R, Huber IS, Rodriguez Amaya DB. Flavonols in fresh and processed Brazillian fruits. J Food Composition Analysis. 2009; 22: 263 - 268.

[6] Jacques AC, Pertuzatti PB, Barcia MT, Zambiazi RC. Nota cientifica: compostos bioativos em pequenas frutas cultivadas na regiao sul do Estado do Rio Grade do Sul. Brazillian J Food Technology. 2009; 12(2): 123 - 127.

[7] Block G, Patterson B, Sbar A. Fruits, vegetables and cancer prevention; a review of the epidemiological evidence. Nutrition and Cancer. 1992; 18(1): 129.

[8] Behl C, Moosmann B. Antioxidant neuroprotection in Alzheimer's disease as preventive and therapeutic approach. Free Rad Biol Medicine. 2002; 33: 182 - 191.

[9] Feskanish D, Ziegler RG, Michaud DS, Giovannucci EL, Spei FE, Willett WC, Colditz GA. Prospective study of fruit and vegetable consumption and risk of lung cancer among men and women. J National Cancer Institute. 2000; 92: 1812 - 1823.

[10] Lima VLAG, Melo EA, Lima DES. fenolicos e carotenoides totais em pitanga. Scientia Agricola. 2002; 59(3): 447450.

[11] Bors W, et al. Flavonoids as antioxidants: determination of radical scavenging efficiencies. Methods in Enzymology. 1990; 186: 343 - 355.

[12] Kris Etherton PM, et al. Bioactive compounds in foods: Their role in the prevention of cardiovascular disease and cancer. American Journal of Medicine. 2002; 113(9): 72-88.

[13] Tapiero H, Townsend DM, Tew KD. The role of carotenoids in the prevention of human pathologies. Biomedicine and Pharmacotherapy. 2004; 58(2): 100-110.

[14] Krisnsky NI, Johnson EJ. Carotenoid actions and their relation to health and disease. Molecular Aspects of Medicine. 2005; 26(6): 459- 516.

[15] Stahl W, Sies H. Bioactivity and protective effects of natural carotenoids. Biochimica et Biophysica Acta. 2005; 1740(2): 101-107.

[16] Kannan RRR, Arumugam R, Meenakshi S, Annantharaman P. Thin layer chromatography analysis of antioxidant constituents from seagrasses of Gulf of Mannar Biosphere Reserve, South India. Int J Chem Tech Res. 2010; 2(3): 1526-1530.

[17] Brand-Williams W, Cuvelier ME, Berset C. Use of the free radical method to evaluate antioxidant activity. Lebensmittel Wissensehaft and Technologie. 1995; 28(1): 25-30.

[18] Bedawey AA. Characterization of antioxidant isolated from some plants sources. Cairo: Shibin El-Kom. 2010; 111.

[19] Nursyahda Zakaria, Razauden Mohamed Zulkifli, Fazrena Nadia Md Akhir, Norazah Basar. 4th International Conference on Mathematics and Natural Sciences (ICMNS 2012), AIP Conf. Proc. 2014; 1589: 288-291.

[20] Adesegun SA, A Fajana CI, Orabueze HAB. Coker. Evaluation of Antioxidant Properties of Phaulopsis Fascisepala CBCI. (Acanthaceae). Oxford J. 2007; 6: 227-213.

[21] Blois MS. Antioxidant determination by the use of stable free radicals. Nature. 1958; 181: 1199-2000. 
[22] Milena B, Elizete MPF, Jaqueline P, Gabriela E H, Delia RA, Cintia NK, Márcia V, Tatiana E. Physicochemical characterization and antioxidant capacity of pitanga fruits (Eugenia uniflora L.). Cienc. Tecnol. Aliment., Campinas. 2011; 31(1): 147-154.

[23] Lim YY, Lim TT, Tee JJ. Antioxidant properties of several tropical fruits: A comparative study. Food Chemistry. 2007; 103(3):1003-1008.

[24] Scalzo J, et al. Plant genotype affects total antioxidant capacity and phenolic contents in fruits. Nutrition. 2005; 21(2): 207-213.

[25] Dr. Jagdev Singh. Acerola (Barbados cherry)-Malpighia Emarginata [Internet]. Ayur Times. [ Cited 2016 May 6] available from https:// www.ayurtimes.com/acerola-barbados-cherry-malpighia-emarginata

\section{Author's short biography}

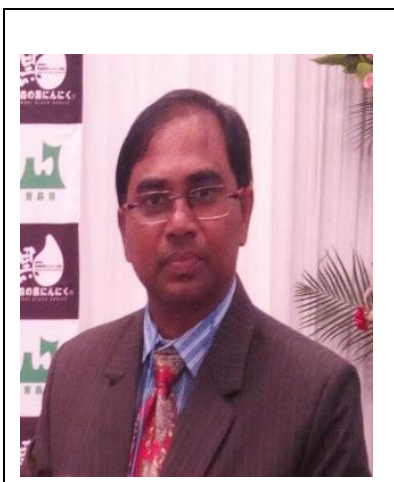

Dr. Subodh Kumar Sarkar, Associate Professor and Chairman, Department of Biochemistry and Molecular Biology, Noakhali Science and Technology University, Noakhali-3814, Bangladesh, working in the field of Food and Natural Products Chemistry since 2002. He has developed three types of Black Garlic (Allium sativum) at the first time in Bangladesh with the collaboration of a Black Garlic Pioneer in Japan, Professor Dr. Jin-Ichi SASAKI, a former Professor of Hirosaki University of Health Sciences in Japan and for his research in Black Garlic in Bangladesh, Dr. Subodh received an Award, "Black Garlic Ambassador" in Bangladesh in the $3^{\text {rd }}$ International Black Garlic Summit in Hachinohe, Japan on September 6, 2018 from Mr. Shinichi Kashiwazaki, President of Black Garlic International Conference \& Aomori Black Garlic Association, Japan. He received research grants from the Ministry of Science and Technology, Government of the People's Republic of Bangladesh, Bangladesh Secretariat, Dhaka-1000, Bangladesh for the year of 2018-2019, 2019-2020 and 2020- 2021 and also received research grants from Research Cell, Noakhali Science and Technology University, Noakhali-3814, Bangladesh for the year of 2018-2019 \& 2020-2021. 